\title{
Exploring the Association of Surface Plasmon Resonance with Recombinant MHC:Ig Hybrid Protein as a Tool for Detecting $T$ Lymphocytes in Mice Infected with Leishmania (Leishmania) amazonensis
}

\author{
Lenilton Silva da Silveira-Júnior, ${ }^{1,2}$ Franklin Souza-Silva, ${ }^{1}$ \\ Bernardo Acácio Santini Pereira, ${ }^{1}$ Léa Cysne-Finkelstein, ${ }^{3}$ \\ Geraldo Barroso Cavalcanti Júnior, ${ }^{2}$ and Carlos Roberto Alves ${ }^{1}$ \\ ${ }^{1}$ Laboratório de Biologia Molecular e Doenças Endêmicas, IOC, Fiocruz, Av. Brasil 4365, 21040-900 Rio de Janeiro, RJ, Brazil \\ ${ }^{2}$ Laboratório de Imunologia Clínica, Departamento de Análises Clınicas e Toxicológicas, Faculdade de Farmácia, \\ Centro de Ciências da Saúde, Universidade Federal do Rio Grande do Norte, Avenida Gustavo Cordeiro de Farias S/N, \\ 59010-180 Natal, RN, Brazil \\ ${ }^{3}$ Laboratório de Imunoparasitologia, IOC, Fiocruz, Av. Brasil 4365, 21040-900 Rio de Janeiro, RJ, Brazil
}

Correspondence should be addressed to Carlos Roberto Alves; calves@ioc.fiocruz.br

Received 20 November 2016; Revised 10 January 2017; Accepted 2 February 2017; Published 8 March 2017

Academic Editor: Abhay Satoskar

Copyright ( 2017 Lenilton Silva da Silveira-Júnior et al. This is an open access article distributed under the Creative Commons Attribution License, which permits unrestricted use, distribution, and reproduction in any medium, provided the original work is properly cited.

\begin{abstract}
A surface plasmon resonance- (SPR-) based recognition method applying H-2 L ${ }^{\mathrm{d}}: \mathrm{Ig} /$ peptides complexes for ex vivo monitoring cellular immune responses during murine infection with Leishmania (Leishmania) amazonensis is described. Lymphocytes from lesion-draining popliteal lymph nodes were captured on a carboxylated sensor chip surface previously functionalized with $\mathrm{H}-2$ $\mathrm{L}^{\mathrm{d}}: \mathrm{Ig}$ (DimerX) protein bound to synthetic peptides derived from the COOH-terminal region of cysteine proteinase $\mathrm{B}$ of $L$. (L.) amazonensis. In computational analysis, these peptides presented values of kinetic constants favorable to form complexes with $\mathrm{H}-2$ $\mathrm{L}^{\mathrm{d}}$ at neutral $\mathrm{pH}$, with a Gibbs free energy $\Delta G^{\circ}<0$. The assayed DimerX:peptide complexes presented the property of attaching to distinct $\mathrm{T}$ lymphocytes subsets, obtained from experimentally infected BALB/c mice, in each week of infection, thus indicating a temporal variation in specific T lymphocytes populations, each directed to a different $\mathrm{COOH}$-terminal region-derived peptide. The experimental design proposed herein is an innovative approach for cellular immunology studies of a neglected disease, providing a useful tool for the analysis of specific T lymphocytes subsets.
\end{abstract}

\section{Introduction}

According to the World Health Organization, leishmaniasis is one of the most neglected diseases in the world with extremely limited investments in the development of diagnosis, treatments, or control management (http://www.who.int/ neglected_diseases/diseases/en). The disease is endemic in tropical and subtropical regions, covering more than 90 countries and territories, affecting mainly the population of developing countries, where more than 350 million people are at risk. It is estimated that 12 million cases exist worldwide, with 2 million new cases occurring each year: 0.5 million of visceral leishmaniasis (VL) and 1.5 million of cutaneous leishmaniasis (CL) $[1,2]$.

The term leishmaniasis comprises a set of clinical manifestations resulting from infection by the obligate intracellular protozoan parasites from the genus Leishmania. One species belonging to this genus is the Leishmania (Leishmania) amazonensis, which is an important etiologic agent of cutaneous leishmaniasis in humans, perhaps most importantly, with varied clinical manifestations in their infections $[3,4]$. 
Leishmania parasites present virulence factors, which confers them the ability to invade and survive within the host, thus possibly causing diseases. Among these factors, we can highlight enzymes, like cysteine-proteinases (CPs), as playing relevant roles in the infection process. One specific $\mathrm{CP}$, which has been reported as a pivotal virulence factor for species of the L. (L.) mexicana complex, is the cysteine proteinase $\mathrm{B}(\mathrm{CPB})$ that presents a characteristic extension of about 100 amino acids at its $\mathrm{COOH}$-terminal region [4]. It has been proposed that, during the intracellular life stage of the parasite, fragments of COOH-terminal region of CPB $L$. (L.) amazonensis (cyspep) may interact with some factors of the immune system of the vertebrate host, including major histocompatibility complex (MHC) proteins [5-7].

In the present manuscript, we propose a new tool for monitoring the $\mathrm{T}$ lymphocytes-linked immune response during the evolution of $L$. (L.) amazonensis infection in mice. Our intent is to construct an adaptable methodology to analyze the molecular/cellular network of events related to antigen presentation in a murine infection.

\section{Materials and Methods}

2.1. Chemicals and Culture Media. Dimethylsulfoxide (DMSO), bovine sera albumin (BSA), $\beta$-mercaptoethanol ( $\beta$ $\mathrm{ME})$, hydroxyethyl piperazineethanesulfonic acid (HEPES), ethylenediaminetetraacetic acid (EDTA), RPMI medium, and Schneider's medium were purchased from Sigma-Aldrich Chemical Co. (St Louis, MO, USA). Fetal calf serum (FCS) was purchased from Gibco, Invitrogen (Brazil). Brain heart infusion (BHI) medium was purchased from Difco (Detroit, MI, USA). The synthetic peptides were produced using N-protected amino fluorenylmethoxy-carbonyl- (Fmoc-) based methodology, purchased from the GenScript Company. Recombinant Soluble Dimeric Mouse H-2L ${ }^{\mathrm{d}}$ :Ig (DimerX) protein and monoclonal antibodies conjugates [phycoerythrin-Cy-7 (PE-Cy7) Hamster anti-mouse CD3e, phycoerythrin (PE) Rat anti-mouse CD4, and fluorescein (FITC) Rat] were purchased from BD Biosciences (Becton, Dickinson and Company, Franklin Lakes, NJ, USA). Coupling agents [1-ethyl-3-(3-dimethylaminopropyl)carbodiimide (EDC) and N-hydroxysuccinimide (NHS)] and ethanolamide were purchased from Merck (Darmstadt, Germany). All other reagents were of analytical grade or superior.

2.2. Cultivation of Parasites. L. (L.) amazonensis (MHOM/ BR/77/LTB0016) promastigotes (obtained from Coleção de Leishmania do Instituto Oswaldo Cruz (CLIOC), IOC, Fiocruz) were grown in Schneider's medium supplemented with $10 \%$ FCS for 4 days at $28^{\circ} \mathrm{C}$. For the experimental infections, the parasites were washed 3 times with $50 \mathrm{mM}$ phosphate buffered saline (PBS) $\mathrm{pH} 7.2$, centrifuged at 2,000 $\times \mathrm{g}$ for $10 \mathrm{~min}$ at $4^{\circ} \mathrm{C}$, counted using a Neubauer chamber, and resuspended in PBS at a concentration of $2.0 \times 10^{7}$ cells $/ \mathrm{mL}$.

2.3. Mice and Experimental Infection. BALB/c 5-7-weekold female mice $\left(\mathrm{H}-2\right.$ haplotype ${ }^{\mathrm{d}}$ ) were obtained from the animal care facility of Fiocruz (Centro de Criação de Animais de Laboratório (CECAL), Fiocruz). For the experimental infections, each animal was inoculated subcutaneously with $1.0 \times 10^{5}$ stationary-phase promastigotes in PBS $(50 \mu \mathrm{L})$ in the left hind paw. For in vitro and ex vivo assays, cells were isolated from the lesion-draining popliteal lymph nodes of five mice infected with $L$. (L.) amazonensis. After isolating and counting the viable cells, these were adjusted and resuspended in RPMI medium supplemented with $2 \%$ FCS $\left(5.0 \times 10^{5}\right.$ cells $\left./ \mathrm{mL}\right)$. All procedures using animals were previously approved by the Animal Ethics Committee of Fiocruz (Comissão de Ética no Uso de Animais (CEUA), Fiocruz; L-0006/07).

2.4. Phenotypic Analysis of T Lymphocytes. The phenotype of the cells from $L$. (L.) amazonensis-infected and noninfected $\mathrm{BALB} / \mathrm{c}$ mice was determined using $1.0 \times 10^{6} \mathrm{lymph}$ node cells. The cells were washed with PBS $\left(500 \times \mathrm{g}, 10 \mathrm{~min}, 4^{\circ} \mathrm{C}\right)$ and resuspended in PBS containing $0.05 \%$ sodium azide and $2 \%$ FBS. Specific monoclonal antibodies Pe-Cy ${ }^{7}$-labeled hamster anti-mouse CD3e IgG, PE-labeled rat anti-mouse CD4 IgG, and FITC-labeled rat anti-mouse CD8a IgG (BD Pharmingen, USA) were added to the cell suspensions, in a 1:100 dilution, and incubated in the dark for $60 \mathrm{~min}$ at $4^{\circ} \mathrm{C}$. Finally, the cells were washed with PBS $(500 \times \mathrm{g}, 10 \mathrm{~min}$, $4^{\circ} \mathrm{C}$ ), resuspended in PBS containing $1 \%$ paraformaldehyde, and analyzed using a BD FACSAria ${ }^{\mathrm{TM}}$ flow cytometer (Becton, Dickinson and Company). For each sample, $2.0 \times$ $10^{4}$ lymphocytes were recorded in list mode and registered on a logarithmic scale histogram. During data acquisition, the volume and inner complexity parameters of the events were controlled to match the typical features of murine lymphocytes. Data analysis was performed using the Summit 4.3 software (DAKO, Fort Collins, CO, USA).

2.5. Chemical Synthesis of Peptides. The cyspep-derived peptides were selected in silico using the SYFPEITHI software (http://www.syfpeithi.de), which uses a combinatory algorithm to predict the potential binding peptides to the $\mathrm{H}-2$ motifs. The purity of the Fmoc-peptides was assessed using reversed-phase liquid chromatography, and the molecular weight was confirmed through mass spectrometry. For use in ex vivo assays, the peptides were completely dissolved at PBS containing $2.0 \mathrm{mg} / \mathrm{mL}$ DMSO and stored at $-20^{\circ} \mathrm{C}$ until further use.

\subsection{Surface Plasmon Resonance Assays}

Surface Functionalization of Sensor Chip (Steps 1 and 2). The functionalization process was performed in eight steps using running buffer (10 mM HEPES, $3 \mathrm{mM}$ EDTA, $150 \mathrm{mM} \mathrm{NaCl}$, and $0.005 \%$ Tween $20, \mathrm{pH} 7.4$ ) at a continuous flow rate (Fr): (i) injection of $10 \mu \mathrm{L}$ of $50 \mathrm{mM} \mathrm{HCl}(\mathrm{Fr}=10 \mu \mathrm{L} / \mathrm{min})$; (ii) injection of $100 \mu \mathrm{L} 10 \mathrm{mM} \mathrm{CH}_{3} \mathrm{COOH}(\mathrm{Fr}=50 \mu \mathrm{L} / \mathrm{min})$; (iii) injection of $150 \mu \mathrm{L}$ of coupling agents (1:1) $400 \mathrm{mM}$ EDC: NHS ( $\mathrm{Fr}=15 \mu \mathrm{L} / \mathrm{min})$; (iv) injection of $100 \mu \mathrm{L} 10 \mathrm{mM}$ $\mathrm{CH} 3 \mathrm{COOH}(\mathrm{Fr}=50 \mu \mathrm{L} / \mathrm{min})$; (v) injection of $100 \mu \mathrm{L}(0.5 \mu \mathrm{g})$ of DimerX H-2 L ${ }^{\mathrm{d}}: \operatorname{Ig}(\mathrm{Fr}=10 \mu \mathrm{L} / \mathrm{min})$; (vi) injection of $100 \mu \mathrm{L}$ $10 \mathrm{mM} \mathrm{CH} 3 \mathrm{COOH}(\mathrm{Fr}=50 \mu \mathrm{L} / \mathrm{min})$; (vii) injection of $150 \mu \mathrm{L}$ 
$100 \mathrm{mM}$ ethanolamine $(\mathrm{Fr}=20 \mu \mathrm{L} / \mathrm{min})$; and (viii) injection of $200 \mu \mathrm{L} 50 \mathrm{mM} \mathrm{HCl}(\mathrm{Fr}=50 \mu \mathrm{L} / \mathrm{min})$.

Complex Formation of $H-2 L^{d}:$ Ig/Peptide (Step 3). Binding of peptides to protein DimerX was performed through the injection of $100 \mu \mathrm{L}$ of each synthetic peptide over the functionalized sensor chip $(\mathrm{Fr}=10 \mu \mathrm{L} / \mathrm{min})$. The peptides $(2 \mathrm{mg} / \mathrm{mL})$ were diluted in filtrated PBS, which was also used as the running buffer. The concentration of peptides for binding to the DimerX was determined according to the manufacturer's instructions:

$$
M_{p}=\mathrm{MH} \cdot R \cdot \frac{D_{p}}{\mathrm{DH}},
$$

where $M_{p}$ is micrograms of the peptide, $\mathrm{MH}$ is micrograms of $\mathrm{H}-2$ in the reaction, $R$ is molar excess $(160 \mathrm{~mol})$ between the peptide and protein $\mathrm{H}-2, D_{p}$ is molecular weight of the peptide, and DH is molecular weight of DimerX $(250,000 \mathrm{Da})$.

Interaction of the Cells with the Complex DimerX/Peptide (Step 4). The reflectance values were expressed as resonance units per second (RU/s). In these assays, the kinetics of association and dissociation between immobilized DimerX/peptide complexes and lymph node cells were determined. These assays were performed with $10^{4}$ cells suspended in PBS in a final volume of $100 \mu \mathrm{L}(\mathrm{Fr}=5 \mu \mathrm{L} / \mathrm{min})$.

Regeneration of the Sensor Chips (Step 5). The regeneration was performed by the injection of $250 \mu \mathrm{L}$ of $30 \mathrm{mM} \mathrm{HCl}(\mathrm{Fr}$ $=50 \mu \mathrm{L} / \mathrm{min}$ ) into the system, followed by the injection of $200 \mu \mathrm{L}$ PBS ( $\mathrm{Fr}=50 \mu \mathrm{L} / \mathrm{min}$ ). After this procedure, only the DimerX molecules were left on the sensor chip surface; thus they were able to form new complexes with different peptides and interact again with cells.

\subsection{Equations Used to Estimate Kinetic Data}

Affinity Constants and Gibbs Free Energy. The affinity (KD) between DimerX and the peptides was obtained from the $k_{a}$ and $k_{d}$ data (see (2)), as determined by the analysis of the kinetics of interaction at $25^{\circ} \mathrm{C}$ in the SPR assays. The following calculation was used to obtain the KD for interactions that rapidly reach equilibrium:

$$
\mathrm{KD}=\frac{k_{d}}{k_{a}} .
$$

The formation of molecular complex between DimerX and peptides complex was also analyzed to calculate the Gibbs free energy of dissociation. This energy is related to the equilibrium constant $\left(K_{\mathrm{eq}}\right)$ of the transition state between the product (DimerX/peptide) and its transient state. The values of $K_{\text {eq }}$ were calculated using the $k_{a}$ and $k_{d}$ data obtained from the SPR assay at $25^{\circ} \mathrm{C}$ :

$$
\Delta G^{\circ}=-\mathrm{RT} \ln \frac{1}{K_{\mathrm{eq}}} .
$$

2.8. Statistical Analysis. To compare results, Student's $t$-test was applied, assuming equal variance between the samples. The assays were performed three times, and the data matrices were considered statistically distinct when $p$ value was lower than 0.05 .

\section{Results and Discussion}

The technology of surface biosensing is a new trend in the characterization of cell surface proteins [8], due to its flexible and powerful ability to detect biomolecular interactions [9]. This method has been successfully applied in the recognition of ligands in mammalian cells $[10,11]$ and in the detection of pathogenic microorganisms present in the environment or food [12]. The analysis by SPR is especially efficient to determine molecular binding events and has been used to assess antigen-antibody interactions and to detect cellular products, such as cytokines, in the supernatant of cultures [13-15].

Additionally, some processes of interaction between parasite and host that involve proteins have been studied with the use of this technology, as the interaction between heparin and circumsporozoite protein of malaria in the parasitic invasion of liver cells [16]. Recent studies by our research group, applying biosensing methods, proved that $L$. (V.) braziliensis promastigotes [17] and Trypanosoma cruzi epimastigotes and trypomastigotes [18] can bind to immobilized heparin, thereby, pointing to the presence of heparin receptors on the surface of these parasites.

The molecular immune network of mice is known to be subverted during infection by Leishmania parasites $[5,19]$. To further understand the mechanisms through which the parasites can interfere with their host immune network, there is a need to develop methodologies able to simulate and to assess, at the molecular level, the interactions that occur during the infection process. Therefore, in the present work, we devised an experimental design that integrates biological and biophysical approaches to partially simulate key events of antigen presentation in experimental murine infection with $L$. (L.) amazonensis, without the need of using specific markers. With this strategy, it was possible to simulate some aspects of the antigen presentation via major histocompatibility complex (MHC) class I to T lymphocytes, once the used fusion protein has characteristics that allow for reproducing in vitro, with reasonable accuracy, the conditions in which epitopes/MHC/T cells receptor interactions occur in vivo [20].

The kinetic parameters of DimerX/peptides complexes were assessed, prior to the ex vivo assay with the mouse cells, to ensure that the assayed peptides could stably bind to the $\mathrm{H}-2$ cleft of DimerX proteins. The DimerX proteins were immobilized onto the sensor chip using the EDC/NHS methodology for covalent binding and, thus, we assumed that the $\alpha 1$ and $\alpha 2$ domains of the recombinant $\mathrm{H}-2$ were free to interact with the synthetic peptides in solution. The RU value obtained after DimerX immobilization was taken as reference to define the baseline to measure peptides binding (Figure 1).

With the data gathered from SPR analysis it was possible to evaluate the kinetics of the interaction between DimerX 
TABLE 1: Peptides from COOH-terminus region of Leishmania (L.) amazonensis CPB and data of H-2LD:Ig interactions.

\begin{tabular}{lccccccc}
\hline ID & Sequences & MW & nmol & $k_{a}$ & $k_{d}$ & KD & 0.0560 \\
\hline P6.3 & EFCLGGGL & 0794.25 & 0.61 & $2.20 \times 10^{8}$ & 0.0560 & -13.0 \\
P6.4 & CLGGGLCL & 0734.20 & 0.54 & $1.20 \times 10^{7}$ & 0.1089 & 09.00 & -11.0 \\
P6.5 & EFCLGGGLC & 0897.35 & 0.70 & $6.40 \times 10^{7}$ & 0.0470 & 00.70 & -12.5 \\
P1.7 & VMVEQVICF & 1067.99 & 0.85 & $1.11 \times 10^{8}$ & 0.1031 & 00.93 & -12.3 \\
P1.9 & MVEQVICFD & 0951.40 & 0.73 & $1.57 \times 10^{6}$ & 0.1157 & 74.00 & -09.7 \\
P1.10 & VEQVICFD & 1082.35 & 0.84 & $1.10 \times 10^{8}$ & 0.1230 & 01.00 & -12.2 \\
\hline
\end{tabular}

ID: identification of peptides; MW: molecular weight of peptides; nmol: molarity; association constant $\left(k_{a} ; \mathrm{M}^{-1} \mathrm{~S}^{-1}\right)$; dissociation constant $\left(k_{d} ; \mathrm{S}^{-1}\right)$; affinity constant (KD; nmolar); free Gibbs energy (Kcal/mol).

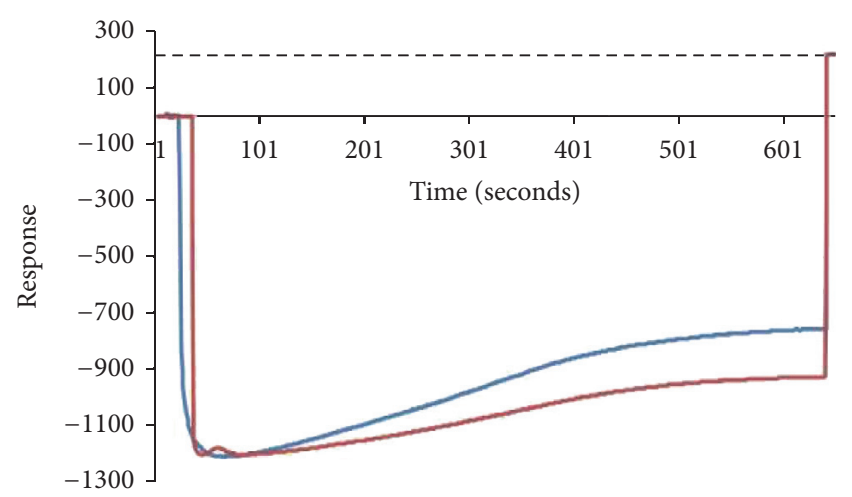

FIGURE 1: Sensorgram graph of $\mathrm{H}-2 \mathrm{~L}^{\mathrm{d}}$ :Ig DimerX protein immobilization on a carboxylated surface sensor chip. Protein immobilization graphs are observed on channels 1 (dark blue) and 3 (dark red). The stabilized dissociation RU values were considered as baseline for posterior studies of DimerX interaction with synthetic peptides. The data are representative of two replicates.

and the peptides. Moreover, it could be observed that the affinity complex formation was variable among the studied peptides (Table 1). Our results suggest that the tested peptides should be capable of stable binding to MHC H-2 L ${ }^{\mathrm{d}}$ cleft and, therefore, of participating in antigen presentation processes. These hypotheses are further corroborated by the values of $k_{d}$ observed for these peptides (varying between $0.047 \mathrm{~s}^{-1}$ and $0.123 \mathrm{~s}^{-1}$ ), which are similar to those described for actual $\mathrm{T}$ lymphocyte epitopes [21].

Additionally, the $\Delta G^{\circ}$ values for the DimerX/peptides complexes were assessed, presenting values below zero, which is an indicative of the spontaneity of these complexes' formation (Table 1). However, it is important to consider that the actual cellular environment in which these complexes interact presents rather distinct physicochemical conditions compared to those observed in the SPR assays. In the cellular microenvironment, the conditions observed are of acidic $\mathrm{pH}$, which is a condition that favors the binding and competition between different peptides to the MHC molecules [22-24], whereas, in the SPR assays, the molecules are tested in a neutral $\mathrm{pH}$ buffer. Nevertheless, the SPR results are relevant in a biological context, as the complexes formed in these assays present kinetic characteristics that should keep them stable on the surface of antigen presenting cells.

The paw lesions evolution and the $\mathrm{CD}^{+}$and $\mathrm{CD}^{+}{ }^{+} \mathrm{T}$ lymphocyte population patterns in BALB/c mice infected with $L$. (L.) amazonensis were assessed and compared to a group of noninfected control animals. These data indicate that the infection (Figure 2(a)) modifies the lymphocyte population profiles causing an increase in CD8+ T lymphocyte population (Figure 2(b)), when compared to control mice (Figure 2(c)). The increase of $\mathrm{CD} 8^{+}$lymphocytes occurs early, in the first weeks of infection, when the lesion size is still discrete (Figure 2(a)) and remains increased throughout the whole analyzed time of infection (Figure 2(b)).

In addition, surface biosensing studies were performed to detect $\mathrm{T}$ lymphocytes reactive to the synthetic peptides, when coupled to the DimerX molecules. The lymphocytes samples used in these essays were previously evaluated which remained morphology preserved throughout the study, with little cell death and suffering during the handling (Figure 3). The used lymph node cells samples present differences in the percentage of $\mathrm{CD} 4+$ and $\mathrm{CD} 8^{+}$lymphocytes when compared to noninfected control mice samples (Figures 3(a) and 3(c)).

Lymph node cells were injected onto SPR chips covered by immobilized DimerX/peptides complexes (Figure 4). In these experiments, due to the complexity to define the kinetic parameters for whole cells, the RU values for association $\left(\mathrm{RU}_{a}\right)$ and dissociation $\left(\mathrm{RU}_{d}\right)$ were used as standards to assess interaction of cells with the complexes. Also, as the stability of $\mathrm{RU}_{d}$ signal over time relates to the stability of interaction, it was used as parameter to define the binding of reactive cells [17].

An assay was performed to assess the possibility of unspecific interaction of lymph node cells with the functionalized chip. In general, $\mathrm{RU}_{a}$ values ranged between 201 and 211 while $\mathrm{RU}_{d}$ values ranged between 168 and 173 in the experiments conducted with cells from infected or noninfected animals on chips containing only immobilized DimerX (Figure 4). These values are markedly distinct from those observed for tests with chips with immobilized DimerX/peptides complexes. In addition, it is relevant to notice that independent of their source (infected or noninfected mice) the cells presented no differences in their $\mathrm{RU}_{a}$ and $\mathrm{RU}_{d}$ values.

Throughout the study, after each test, the surface of the sensor chip was regenerated with $\mathrm{HCl}$, as described in 


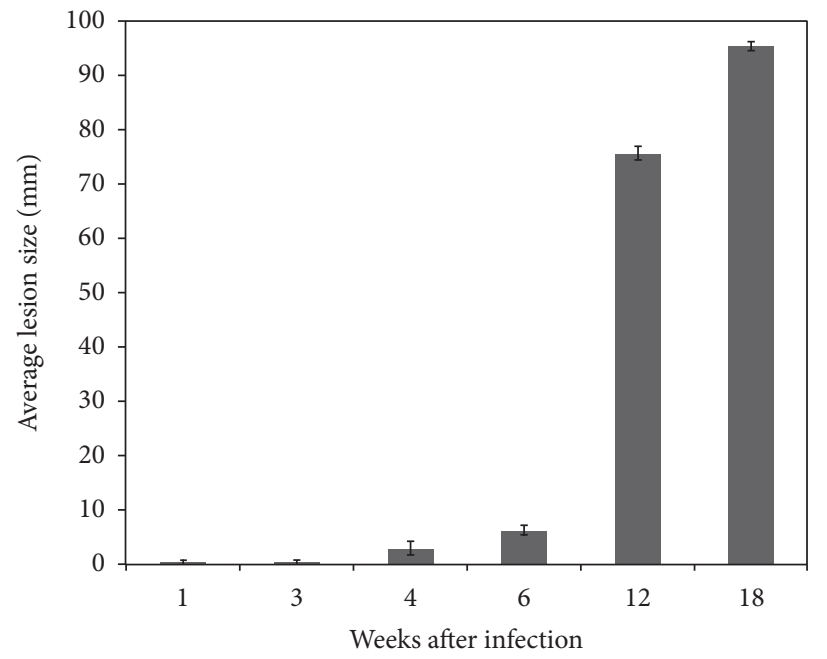

(a)

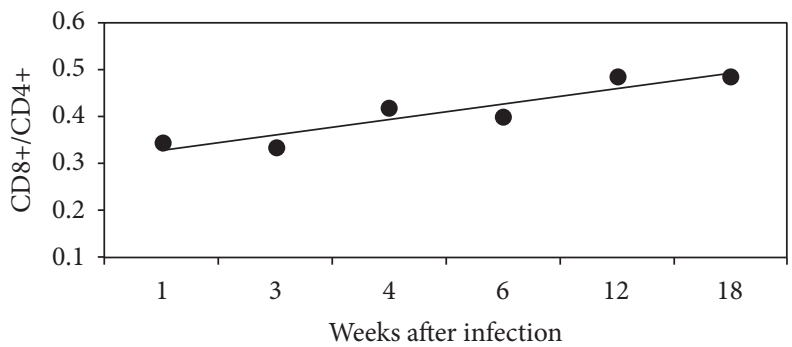

(b)

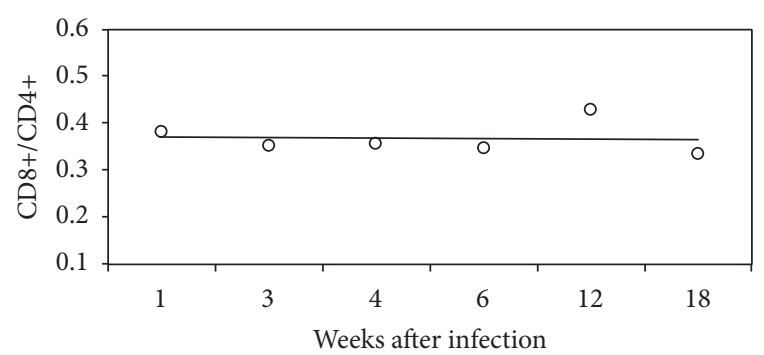

(c)

Figure 2: Profiles of lesion growth and $\mathrm{CD} 4^{+} / \mathrm{CD} 8^{+} \mathrm{T}$ lymphocyte populations in BALB/c mice infected with $L$. (L.) amazonensis. Animals were inoculated subcutaneously with $1.0 \times 10^{5}$ promastigotes in the plantar cushion of the left hind paw and lesions were monitored weekly by measuring the height $(h)$ and width $(w)$ of the cushion with a pachymeter (a). The results represent the lesion size $(h \times w)$ mean \pm standard deviation (SD) of five animals, in millimeters $(\mathrm{mm})$. The immunological profile of the popliteal lymph node cells was determined by flow cytometry in groups of infected (b) and noninfected (c) animals. The values of the CD $8^{+} / \mathrm{CD} 4^{+}$ratio indicate an increase in the CD8+ lymphocyte population in animals infected with $L$. (L) amazonensis. The data are representative of three independents experiments performed in triplicate.

the methodology. Generally, the data responses indicated significant values $(p<0.05)$ of regeneration RU below the interaction $\mathrm{H}-2 \mathrm{~L}^{\mathrm{d}}: \mathrm{Ig} /$ peptide for cells from noninfected and infected mice (Figure 5). From this data, it was possible to affirm that the $\alpha 1 / \alpha 2$ domains of $\mathrm{H}-2 \mathrm{~L}^{\mathrm{d}}$ :Ig were set free for a new interaction.

Furthermore, experimental evidences support the hypothesis that the binding of the cells from infected mice to the immobilized complexes is specific, once the $\mathrm{RU}_{d}$ values obtained for these interactions were consistently higher that those observed for the interaction of cells from noninfected mice. The RU values obtained by the subtraction of the nonspecific interaction RU (cells from noninfected animals) from the specific interaction RU (cells from infected mice) were considered as representative of the binding effectiveness (Table 2). These effectiveness RU values allowed observing a different trend of $\mathrm{T}$ lymphocytes recognition for each peptide tested throughout the experimental infection timeline (Table 2).

Although T lymphocytes reactive to peptides P1.7, P6.3, and P1.10 have shown a clear tendency to diminish their reactivity along the infection, the cells reactive to peptides P1.9, P6.4, and P6.5 showed an oscillation in their reactivity, in general without a clear ascending or descending pattern. However, all reactive cells showed a reduction in their reactivity at the 18th week after infection. These data suggest that these peptides are of low immune significance in the late stages of infection, while they were much more significant, as determined by the number of reactive $\mathrm{T}$ lymphocytes, in the earlier infection stages. Their significance in this time point may render them as decisive factors for the establishment of the infection in $\mathrm{BALB} / \mathrm{c}$ mice.

Moreover, it is also possible that the low detection of reactive $T$ cells observed in the later stages of infection is due to the presence of lymphocytes primed to apoptosis, with an affected antigen recognition ability. Although the presence of such apoptotic T lymphocytes in mice lesions has already been reported [25], flow cytometry assays performed to confirm these cells in our lymph node preparation did not detect any such cells (data not shown).

The results presented herein correspond to a first surface biosensing-based approach applied to the detection of 


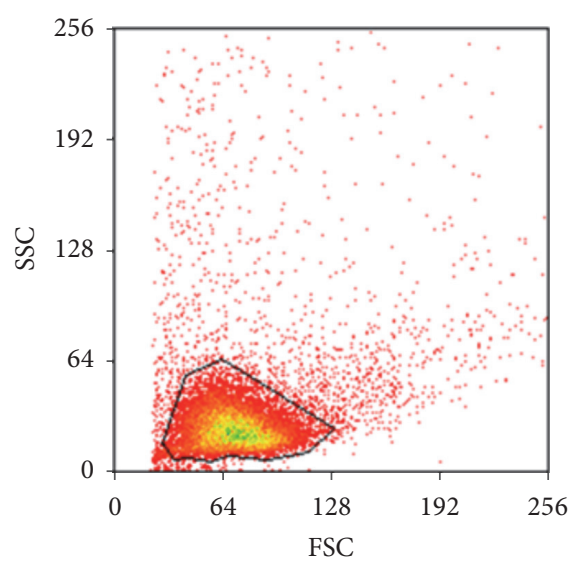

(a)
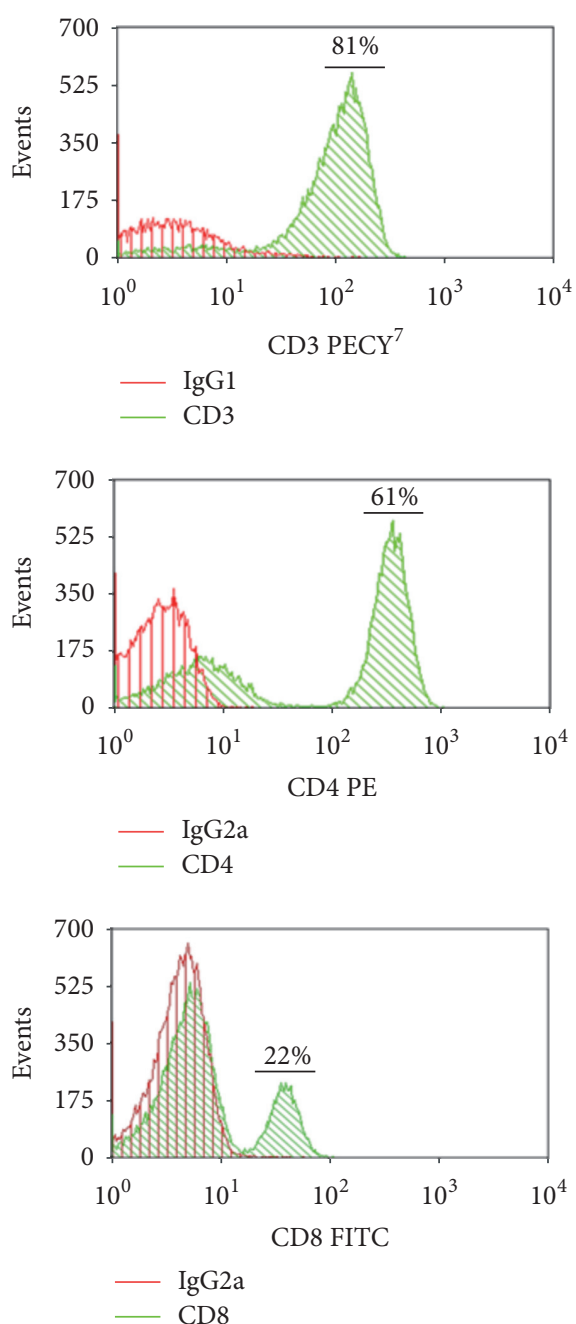

(c)

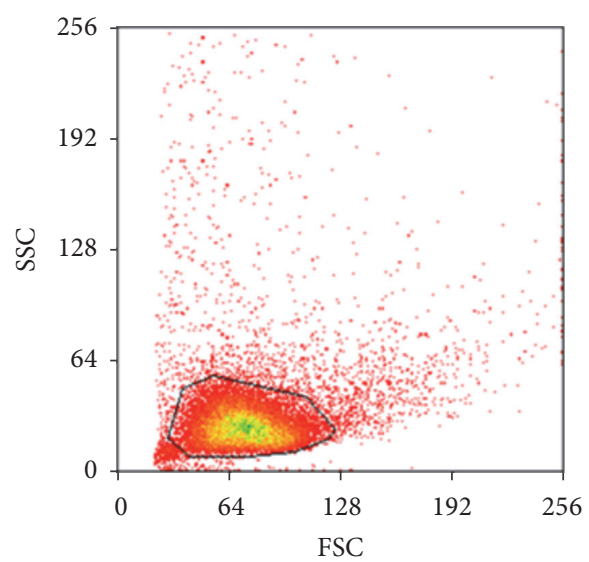

(b)
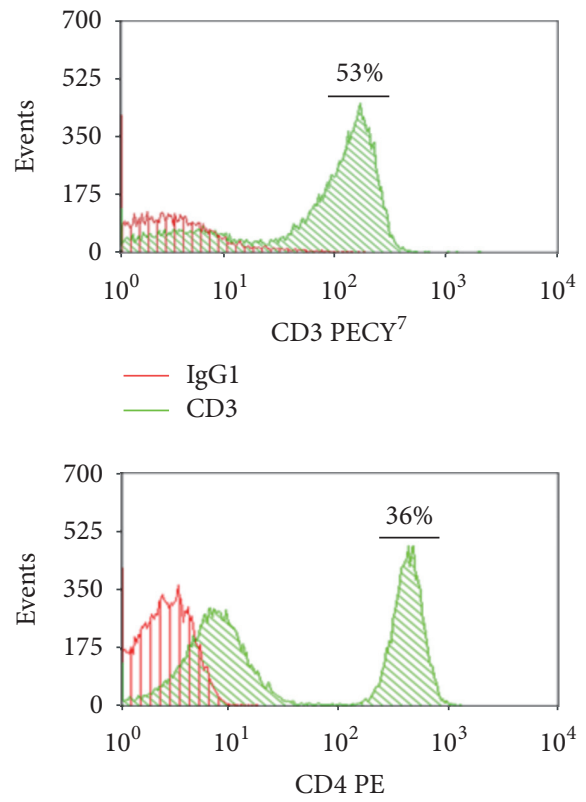

- IgG2a

- CD4

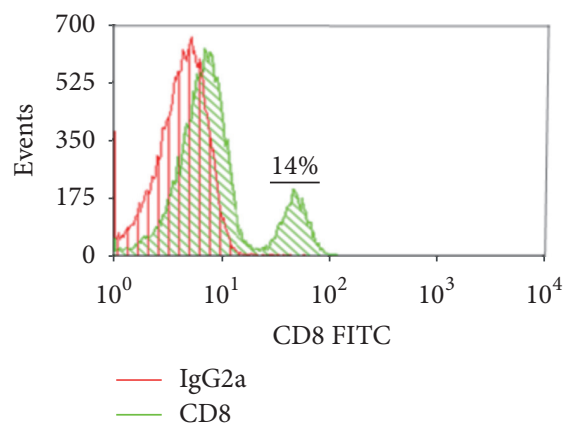

(d)

FIGURE 3: Graphic representations of flow cytometry. Dot plots were based on the evaluation of the gate analysis (a and b), delimiting the area of lymphocytes; we may infer that the morphology of the cells remained preserved throughout the study, which indicates that there were little cell death and suffering during the procedure to obtain them. The data are for the noninfected (a) and infected (b) mice group with $L$. ( $L$.) amazonensis. Histogram superposition ( $\mathrm{c}$ and $\mathrm{d}$ ) shows the control isotype in the low fluorescence intensity, corresponding to negative region $\left(0\right.$ to $\left.10^{1}\right)$, as signals above this range were considered positive reactions $\left(10^{2}-10^{3}\right)$. This distance between areas of negative and positive signal is indicative of a good reaction receptor blocking unspecific binding. Moreover, the data show that there is a difference in the percentage of lymphocytes when comparing the noninfected (c) and infected (d) mice group with $L$. (L.) amazonensis. These data are representative of three replicates of lymph node cells analysis from 4 th week of mice infection. 
TABLE 2: Response data from subtractive dissociation between the response dissociation of cells from infected and noninfected mice with Leishmania (L.) amazonensis.

\begin{tabular}{|c|c|c|c|c|c|c|}
\hline ID & $\begin{array}{c}\mathrm{RU}_{s} \\
\text { 1st week }\end{array}$ & $\begin{array}{c}\mathrm{RU}_{s} \\
\text { 3rd week }\end{array}$ & $\begin{array}{c}\mathrm{RU}_{s} \\
\text { 4th week }\end{array}$ & $\begin{array}{c}\mathrm{RU}_{s} \\
\text { 6th week }\end{array}$ & $\begin{array}{c}\mathrm{RU}_{s} \\
\text { 12th week }\end{array}$ & $\begin{array}{c}\mathrm{RU}_{s} \\
\text { 18th week }\end{array}$ \\
\hline P1.7 & 161 & 102 & 96 & 115 & DNS & 0.0 \\
\hline P1.9 & 115 & 181 & 149 & 118 & 120 & 66 \\
\hline P1.10 & DNS & 227 & DNS & 123 & 31 & 44 \\
\hline P6.3 & DNS & 216 & 187 & 113 & 35 & 57 \\
\hline P6.4 & DNS & 100 & 127 & 140 & DNS & 66 \\
\hline P6.5 & DNS & 55 & 185 & 109 & 27 & 85 \\
\hline
\end{tabular}

ID: identification of peptides; $\mathrm{RU}_{s}$ : subtractive dissociation response; DNS: data not shown.

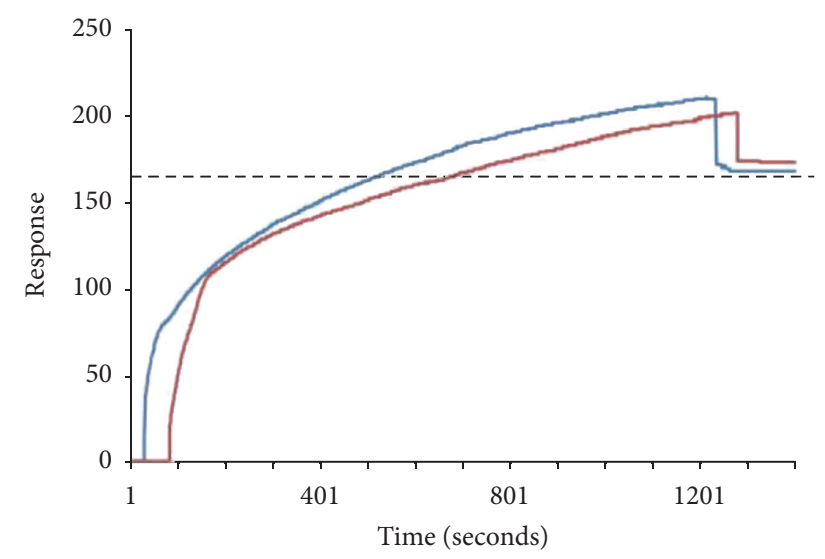

Figure 4: Sensorgram graph of DimerX interaction with BALB/c mice lymph node cells. The experiments were conducted with cells obtained from L. (L.) amazonensis-infected (dark blue) or noninfected (dark red) mice. The functionalized sensor chips were recovered with DimerX proteins without complexed peptides. The data are representative of two independents experiments performed in triplicate.

potential immunoregulatory T lymphocytes in experimental murine infection by L. (L.) amazonensis. Even though the SPR technique may present some limitations to detect whole cell due to their dimensions, which can lead to mass transport issues on the surface of the sensor chip, this methodology has been showing promising results in tracking cells with important biological activity, as recently described for detecting osteogenic cells [26].

The biosensing-based approach to determine the T lymphocyte phenotype proposed herein requires further discussion. The H-2 Ld:Ig construction was originally designed to study $\mathrm{T}$ lymphocyte function by immunofluorescence staining and flow cytometric analysis of antigen-specific $\mathrm{T}$ lymphocytes. In the present work, we devised an innovative application for this construction, applying it to the analysis of specific T lymphocytes, based on the concept that class I proteins bind to CD8+ T lymphocyte. Thus, the RU signal detected by using $\mathrm{H}-2 \mathrm{Ld}: \mathrm{Ig} /$ peptide complexes relates to
$\mathrm{CD}^{+} \mathrm{T}$ lymphocytes, as the complex formed by class I protein and a binding peptide is recognized by and adheres to $\mathrm{CD}^{+} \mathrm{T}$ lymphocyte [27].

It is also noteworthy that one of the advantages of the association of SPR with DimerX is the possibility of analyzing the binding phenomenon directly on the surface of lymphocytes, in real time. The data generated by this approach has the potential to reflect, in many aspects, the actual process of antigen recognition by $\mathrm{T}$ cells, as a fourth dimension (time) is considered in the establishment of molecular interactions [28]. Additional studies are needed to further refine these analyses into quantifying the lymphocytes clones present in the lymph node suspensions, as it has been proposed for the quantification of Escherichia coli [29].

\section{Conclusions}

We present a series of experiments to propose an innovative approach in immunoparasitology of Leishmania, using SPRbased methods for detecting antigen-reactive T lymphocytes in mice. The SPR data were useful to indicate that T lymphocytes specifically reactive to peptides from the region $\mathrm{COOH}-$ terminal cysteine proteinase B from $L$. (L.) amazonensis can be detected even in the early stages of the infection and present distinct variations in their populations throughout the infection. This fact is further evidence that cysteine proteinase $B$ may contribute in interactions with the immune system of mice and affect the outcome of experimental infection.

\section{Authors' Contributions}

All authors approved the final version of the manuscript.

\section{Disclosure}

Carlos R. Alves is a fellow researcher at CNPq institution.

\section{Conflicts of Interest}

All authors declare no competing financial interest. 


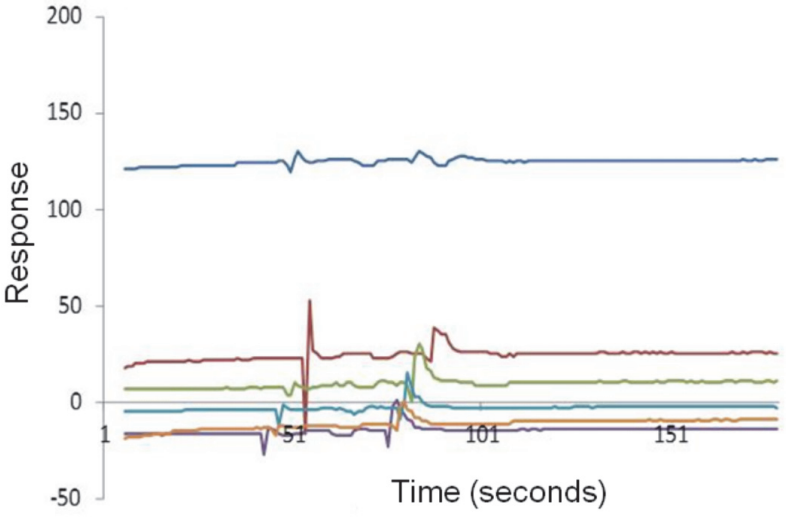

(a)

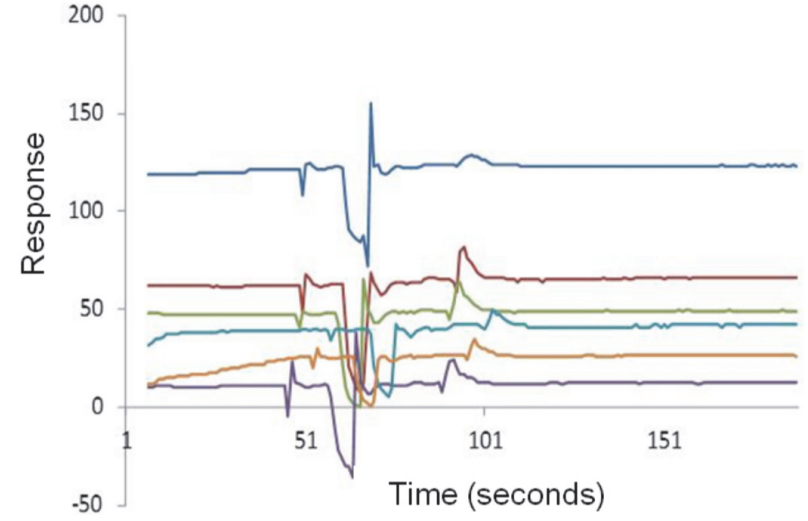

(b)

Figure 5: Interaction between immobilized DimerX/peptides complexes and lymph node cells preparations. The assays were performed with cells from L. (L.) amazonensis-infected (a) or noninfected (b) mice, which were streamed over a sensor chip containing the immobilized complexes. After each step of cell binding, the cells and peptides were removed with $30 \mathrm{mM} \mathrm{HCl}$ solution, leaving $\alpha 1 / \alpha 2$ domains of the DimerX proteins free for a further interaction cycle. Sensorgram graphs are representative of all regeneration cycles $(n=120)$ and show the RU values for assayed peptides (P1.7 dark blue; P1.9 dark red; P1.10 green; P6.3 purple; P6.4 blue; P6.5 orange) during 151 seconds. The data are representative of three independents experiments performed in triplicate.

\section{Acknowledgments}

The authors thank the Surface Plasmon Resonance (RPT03E) and Multiuser Research Facility of Flow Cytometry-Parametric Analysis, Instituto Oswaldo Cruz, both technological platforms of Fundação Oswaldo Cruz, for their support in the assays. This research was supported by grants from Brazilian research agencies as PAPES V-CNPq/Fiocruz (300731/20108), CNPq (509737/2010-2), CAPES (EDITAL, 11/2009), and FAPERJ (E-26/103.060/2008, E-26/110.257/2010).

\section{References}

[1] L. Rivas, J. Moreno, C. Cañavate, and J. Alvar, "Virulence and disease in leishmaniasis: what is relevant for the patient?" Trends in Parasitology, vol. 20, no. 7, pp. 297-301, 2004.

[2] B. Chawla and R. Madhubala, "Drug targets in Leishmania," Journal of Parasitic Diseases, vol. 34, no. 1, pp. 1-13, 2010.

[3] A. Barral, D. Pedral-Sampaio, G. Grimaldi Jr. et al., "Leishmaniasis in Bahia, Brazil: evidence that Leishmania amazonensis produces a wide spectrum of clinical disease," American Journal of Tropical Medicine and Hygiene, vol. 44, no. 5, pp. 536-546, 1991.

[4] J. C. Mottram, G. H. Coombs, and J. Alexander, "Cysteine peptidases as virulence factors of Leishmania," Current Opinion in Microbiology, vol. 7, no. 4, pp. 375-381, 2004.

[5] B. A. S. Pereira and C. R. Alves, "Immunological characteristics of experimental murine infection with Leishmania (Leishmania) amazonensis," Veterinary Parasitology, vol. 158, no. 4, pp. 239-255, 2008.

[6] B. A. S. Pereira, F. S. Silva, K. M. Rebello et al., "In silico predicted epitopes from the $\mathrm{COOH}$-terminal extension of cysteine proteinase $\mathrm{B}$ inducing distinct immune responses during Leishmania (Leishmania) amazonensis experimental murine infection," BMC Immunology, vol. 12, article no. 44, 2011.

[7] B. A. S. Pereira, C. Britto, and C. R. Alves, "Expression of infection-related genes in parasites and host during murine experimental infection with Leishmania (Leishmania) amazonensis," Microbial Pathogenesis, vol. 52, no. 2, pp. 101-108, 2012.

[8] M. N. Velasco-Garcia, "Optical biosensors for probing at the cellular level: a review of recent progress and future prospects," Seminars in Cell and Developmental Biology, vol. 20, no. 1, pp. 27-33, 2009.

[9] F. A. Tanious, B. Nguyen, and W. D. Wilson, "Biosensorsurface plasmon resonance methods for quantitative analysis of biomolecular interactions," Methods in Cell Biology, vol. 84, pp. 53-77, 2008.

[10] J. G. Quinn, S. O’Neill, A. Doyle et al., "Development and application of surface plasmon resonance-based biosensors for the detection of cell-ligand interactions," Analytical Biochemistry, vol. 281, no. 2, pp. 135-143, 2000.

[11] M. Hide, T. Tsutsui, H. Sato et al., "Real-time analysis of ligand-induced cell surface and intracellular reactions of living mast cells using a surface plasmon resonance-based biosensor," Analytical Biochemistry, vol. 302, no. 1, pp. 28-37, 2002.

[12] A. A. Bergwerff and F. Van Knapen, "Surface plasmon resonance biosensors for detection of pathogenic microorganisms: strategies to secure food and environmental safety," Journal of AOAC International, vol. 89, no. 3, pp. 826-831, 2006.

[13] T. M. Battaglia, J.-F. Masson, M. R. Sierks et al., "Quantification of cytokines involved in wound healing using surface plasmon resonance," Analytical Chemistry, vol. 77, no. 21, pp. 7016-7023, 2005.

[14] T.-H. Chou, C.-Y. Chuang, and C.-M. Wu, "Quantification of Interleukin-6 in cell culture medium using surface plasmon resonance biosensors," Cytokine, vol. 51, no. 1, pp. 107-111, 2010.

[15] G. Stybayeva, M. Kairova, E. Ramanculov, A. L. Simonian, and A. Revzin, "Detecting interferon-gamma release from human CD4 T-cells using surface plasmon resonance," Colloids and Surfaces B: Biointerfaces, vol. 80, no. 2, pp. 251-255, 2010.

[16] D. Rathore, T. F. McCutchan, D. N. Garboczi et al., "Direct measurement of the interactions of glycosaminoglycans and a heparin decasaccharide with the malaria circumsporozoite protein," Biochemistry, vol. 40, no. 38, pp. 11518-11524, 2001. 
[17] L. M. Côrtes, R. M. Silva, B. A. Pereira et al., "Lulo cell line derived from Lutzomyia longipalpis (Diptera: Psychodidae): a novel model to assay Leishmania spp. and vector interaction," Parasites and Vectors, vol. 4, no. 1, article no. 216, 2011.

[18] F. O. R. Oliveira Jr., C. R. Alves, F. Souza-Silva et al., "Trypanosoma cruzi heparin-binding proteins mediate the adherence of epimastigotes to the midgut epithelial cells of Rhodnius prolixus," Parasitology, vol. 139, no. 6, pp. 735-743, 2012.

[19] M. Silva-Almeida, B. A. S. Pereira, M. L. Ribeiro-Guimarães, and C. R. Alves, "Proteinases as virulence factors in Leishmania spp. infection in mammals," Parasites and Vectors, vol. 5, article 160, 2012.

[20] S. N. Khilko, M. T. Jelonek, M. Corr, L. F. Boyd, A. L. M. Bothwell, and D. H. Margulies, "Measuring interactions of MHC class I molecules using surface plasmon resonance," Journal of Immunological Methods, vol. 183, no. 1, pp. 77-94, 1995.

[21] P. E. Jensen and A. O. Kraft, "T cells from nonresponder mice: MHC restricted and unrestricted recognition of insulin," Journal of Immunology, vol. 145, no. 12, pp. 3985-3991, 1990.

[22] C. V. Harding, R. W. Roof, P. M. Allen, and E. R. Unanue, "Effects of $\mathrm{pH}$ and polysaccharides on peptide binding to class II major histocompatibility complex molecules," Proceedings of the National Academy of Sciences of the United States of America, vol. 88, no. 7, pp. 2740-2744, 1991.

[23] S. Sadegh-Nasseri and R. N. Germain, "A role for peptide in determining MHC class II structure," Nature, vol. 353, no. 6340, pp. 167-170, 1991.

[24] P. A. Reay, D. A. Wettstein, and M. M. Davis, "pH dependence and exchange of high and low responder peptides binding to a class II MHC molecule," EMBO Journal, vol. 11, no. 8, pp. 28292839, 1992.

[25] S. T. Kanaly, M. Nashleanas, B. Hondowicz, and P. Scott, "TNF receptor p55 is required for elimination of inflammatory cells following control of intracellular pathogens," Journal of Immunology, vol. 163, no. 7, pp. 3883-3889, 1999.

[26] Y.-C. Kuo, J. H. Ho, T.-J. Yen, H.-F. Chen, and O. K.-S. Lee, "Development of a surface plasmon resonance biosensor for Real-Time detection of osteogenic differentiation in live mesenchymal stem cells," PLoS ONE, vol. 6, no. 7, Article ID e22382, 2011.

[27] S. Hulpke and R. Tampé, "The MHC I loading complex: a multitasking machinery in adaptive immunity," Trends in Biochemical Sciences, vol. 38, no. 8, pp. 412-420, 2013.

[28] M. H. V. Van Regenmortel, "Mapping epitope structure and activity: from one-dimensional prediction to four-dimensional description of antigenic specificity," Methods: A Companion to Methods in Enzymology, vol. 9, no. 3, pp. 465-472, 1996.

[29] Y. Wang, Z. Ye, C. Si, and Y. Ying, "Subtractive inhibition assay for the detection of E. coli O157:H7 using surface plasmon resonance," Sensors, vol. 11, no. 3, pp. 2728-2739, 2011. 


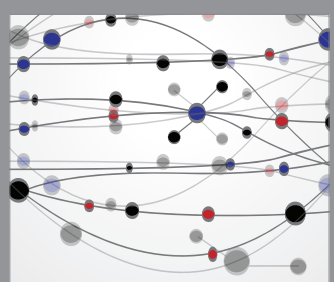

The Scientific World Journal
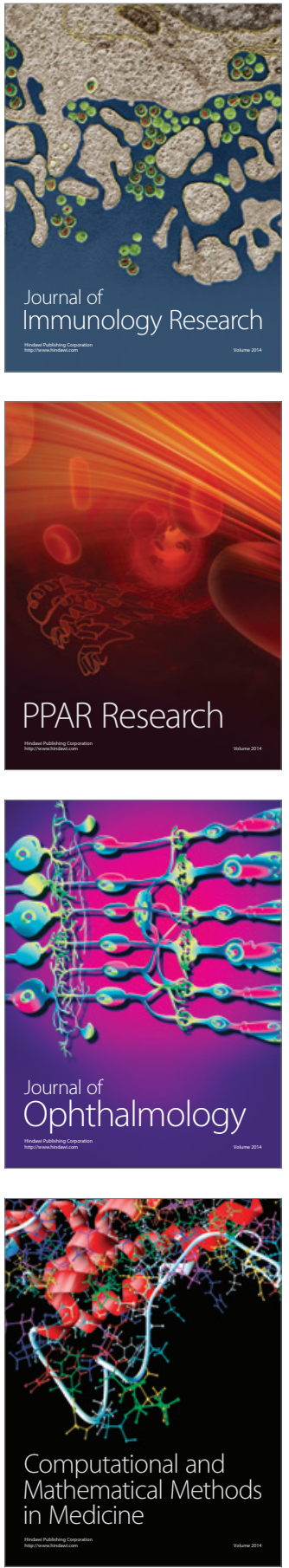

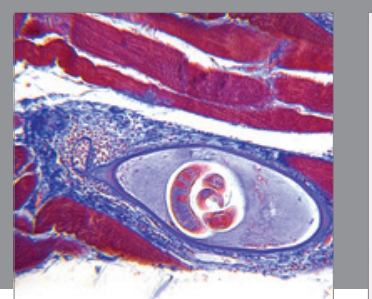

Gastroenterology Research and Practice
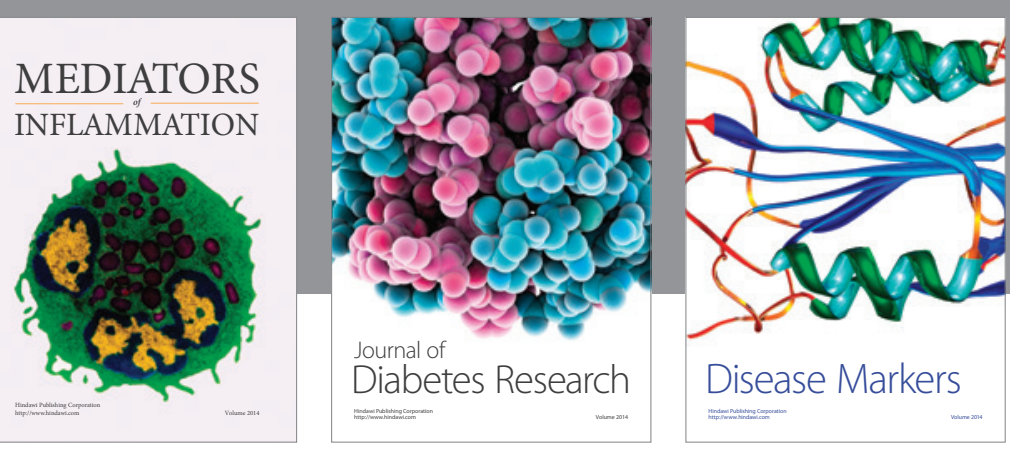

Disease Markers

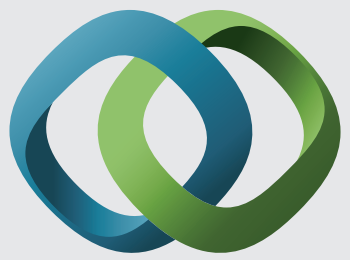

\section{Hindawi}

Submit your manuscripts at

https://www.hindawi.com
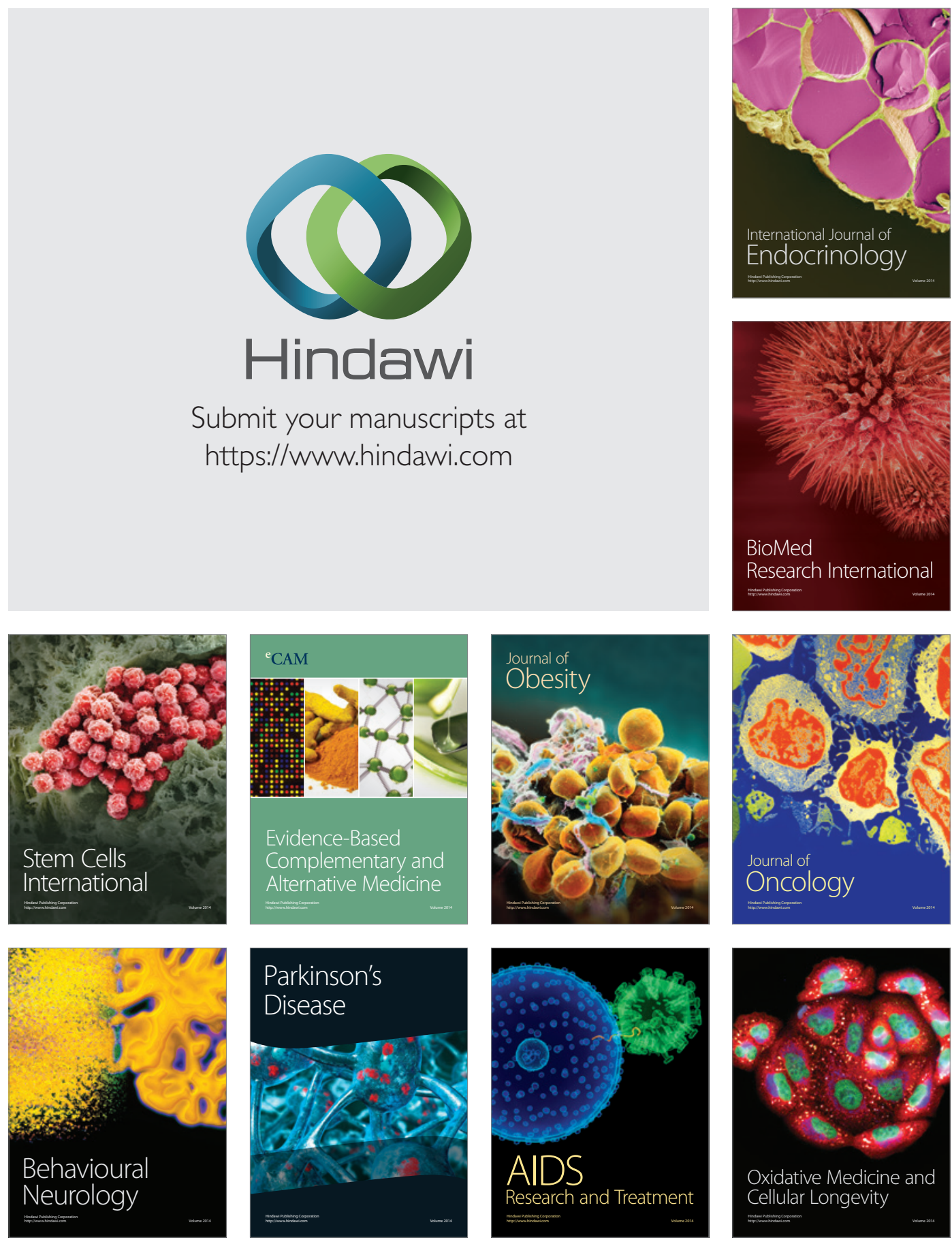